
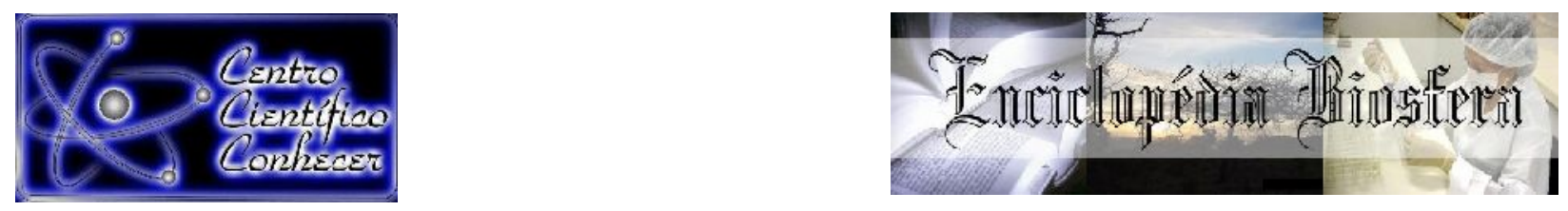

\title{
ESTUDO DA FORMAÇÃO DE BIOFILME POR RIZOBACTÉRIAS ISOLADAS DE NÓDULOS DE RAÍZES DE ARROZ DE SEQUEIRO (Oryza sativa) CULTIVADO NO CERRADO GOIANO
}

Maurício de Sousa Oliveira'; Valdirene Neves Monteiro²; Cláudia Cristina Garcia Martin Didonet ${ }^{2+}$; Plínio Lázaro Faleiro Naves ${ }^{2,3^{*}}$

${ }^{1}$ Mestre em Ciências Moleculares - Universidade Estadual de Goiás, Campus Central de Ciências Exatas e Tecnológicas. Anápolis-GO.

2 Professores do Programa de Pós-Graduação em Ciências Aplicadas a Produtos para Saúde. Universidade Estadual de Goiás, Campus Central de Ciências Exatas e Tecnológicas. BR-153, CEP 75132-903, Anápolis-GO.

${ }^{3}$ Professor do Programa de Pós-Graduação em Ciências Moleculares. Universidade Estadual de Goiás, Campus Central de Ciências Exatas e Tecnológicas. BR-153,

CEP 75132-903, Anápolis-GO.

*Autor correspondente: plinionaves@ueg.br + in memorian

\section{Recebido em: 15/11/2021 - Aprovado em: 15/12/2021 - Publicado em: 30/12/2021 DOI: 10.18677/EnciBio 2021D24}

trabalho licenciado sob licença Creative Commons Attribution-NonCommercial-NoDerivatives 4.0 International License

\section{RESUMO}

A formação de biofilme microbiano tem um papel fundamental nas relações entre plantas e bactérias, principalmente na rizosfera. Este trabalho avaliou o desempenho de três meios de cultura distintos (RDM - Rhizobium defined medium, YM - yeast manitol e CB - caldo batata) na formação de biofilme por 15 rizobactérias isoladas de nódulos das raízes de arroz de sequeiro (Oryza sativa) cultivado no Cerrado goiano. Todas as rizobactérias foram capazes de formar biofilmes nos meios de cultura testados. Os índices de formação de biofilme (IFB) mais altos foram detectados para a rizobactéria $\mathrm{R} 134(37,18 \pm 1,79)$ no meio $\mathrm{YM}$ e para $\mathrm{R} 58$ nos meios RDM $(33,21 \pm 0,44)$ e $Y M(33,77 \pm 1,11)$. Os IFB mais baixos foram detectados em CB para BR322 $(3,44 \pm 1,14)$ e R5 $(6,10 \pm 0,56)$. As rizobactérias com a maior porcentagem de leitura da viabilidade das células associadas aos biofilmes foram $R 82(77,41 \pm 0,79)$ em RDM, BR522 $(76,85 \pm 0,59)$ no CB, R127 $(75,07 \pm 0,50)$ em meio YM e R31 $(74,74 \pm 1,09)$ em CB e as menores leituras foram para R132 e R125a em todos os meios e para R59 em cb. Na análise entre os meios CB e YM, constatou-se que diferenças significativas para os parâmetros de biomassa total (BMT) $(P=0,0125)$ e crescimento celular $(P=0,0001)$, sendo o meio $C B$ mais efetivo nestas duas avaliações. O meio YM proporcionou o desenvolvimento de biofilmes bacterianos com altos índices de células viáveis e de matriz polimérica extracelular.

PALAVRAS-CHAVE: biofilme; biomassa; meios de cultura; viabilidade celular. 


\title{
STUDY OF BIOFILM FORMATION BY RHIZOBACTERIA ISOLATED FROM NODULES OF UPLAND RICE PLANTS (Oryza sativa) CULTIVATED IN THE SAVANNA OF GOIÁS, BRAZIL
}

\begin{abstract}
The formation of microbial biofilm plays a fundamental role in the relationships between plants and bacteria, especially in the rhizosphere. In this work, we evaluated the performance of three different culture media (RDM - Rhizobium defined medium, YM - yeast mannitol and CB - potato broth) on biofilm formation by 15 rhizobacteria isolated from nodules of roots of upland rice plants (Oryza sativa) cultivated in the savanna of Goiás state in Brazil. All rhizobacteria were able to form biofilms in the culture media tested. The highest biofilm formation indices (IFB) were detected for R134 rhizobacteria (37.18 \pm 1.79$)$ in the YM medium and for R58 in the RDM (33.21 $\pm 0.44)$ and YM $(33.77 \pm 1.11)$ media and the lowest in the broth potato for strains BR322 (3.44 \pm 1.14$)$ and R5 (6.10 \pm 0.56$)$. The rhizobacteria with the highest percentage of cell viability associated with biofilms were R82 (77.41 \pm 0.79$)$ in RDM, BR522 (76.85 \pm 0.59$)$ in potato broth, R127 (75.07 \pm 0.50$)$ in YM medium and R31 (74.74 \pm 1.09$)$ in potato broth and the lowest readings were for R132 and R125a in all media and for R59 in potato broth. In the analysis between the CB and YM media, it was found that there was a significant difference for the parameters of total biomass (BMT) $(P=0.0125)$ and cell growth $(P=0.0001)$, with the $C B$ medium being more effective in these two evaluations. YM medium provided the development of bacterial biofilms with high levels of viable cells and extracellular polymeric matrix.
\end{abstract}

KEYWORDS: biofilm; biomass; cell viability; culture media.

\section{INTRODUÇÃO}

A interação entre rizobactérias e plantas é de fundamental importância agronômica e ambiental, pois torna possível a produção de culturas em solos deficientes de nitrogênio, por meio da diminuição ou até mesmo ausência do fornecimento de fertilizantes nitrogenados (NUMAN et al., 2018; REZENDE et al., 2021).

Rizobactérias constituem um amplo grupo de micro-organismos que podem adotar o crescimento na forma de biofilmes como estratégia para interação na rizosfera e desempenham importante papel como promotoras do crescimento vegetal por meio da conversão de nitrogênio atmosférico em compostos assimiláveis que afetam beneficamente o desenvolvimento vegetal e possuem um interessante potencial para produção de biofertilizantes, fixação biológica de nitrogênio, produção de fitohormônios, produção e solubilização de fosfatos, ou indiretamente através da indução de resistência a patógenos (GOUDA et al., 2018; ALOO et al., 2019 REZENDE et al., 2021).

A interação entre rizobactérias e plantas é de fundamental importância agronômica e ambiental, pois torna possível a produção de culturas em solos deficientes de nitrogênio, por meio da diminuição ou até mesmo ausência do fornecimento de fertilizantes nitrogenados (AERON et al., 2020). O estabelecimento da simbiose entre a planta e a bactéria requer a formação do biofilme, sendo que essa particularidade é um processo sequencial de desenvolvimento que culmina no estabelecimento das comunidades bacterianas (WANG et al., 2020). Na natureza, os micro-organismos encontram-se em comunidades com diferentes graus de complexidade estrutural denominadas de biofilmes (COSTA et al., 2016). Biofilmes são comunidades ou agregados microbianos envoltas por uma matriz polimérica de 
aspecto gelatinoso, aderidas a uma superfície sólida biótica ou abiótica (MUHSIN et al., 2018). São constituídos essencialmente por um ou mais tipos de microorganismos, por suas substâncias poliméricas extracelulares autoproduzidas e por água. Configuram uma estrutura complexa de microcolônias e canais verticais e horizontais que permitem o fluxo de fluidos, a dispersão de nutrientes e resíduos (HATHROUBI et al., 2018; MUHAMMAD et al., 2020; BOURIGAULT et al., 2021).

A formação e o desenvolvimento do biofilme se dão em resposta a estímulos ambientais específicos, como por exemplo, a disponibilidade de nutrientes, temperatura, $\mathrm{pH}$, força iônica, velocidade de escoamento, tipo e rugosidade do material, presença de material particulado, de micronutrientes e agentes antimicrobianos. Contudo esse processo é estritamente dependente do tipo de micro-organismo em questão (CHOUDHARY et al., 2020).

As principais metodologias utilizadas como ensaios para quantificação de biofilme em microplacas podem ser classificadas em três grupos. Ensaios de biofilme biomassa os quais são baseados na quantificação da matriz, células vivas e mortas. Ensaios de viabilidade com base na quantificação de células viáveis e ensaios de quantificação de matriz baseado na coloração específica dos componentes da matriz (PEETERS et al., 2008).

Neste contexto, o presente trabalho objetiva determinar o índice de formação de biofilme e a viabilidade das células associadas de rizobactérias isoladas de nódulos plantas de arroz de sequeiro (Oryza sativa) cultivado no cerrado goiano em três meios de cultura distintos: RDM - Rhizobium defined medium, YM - yeast manitol e CB - caldo batata.

\section{Rizobactérias empregadas e condições de cultivo \\ MATERIAL E MÉTODOS}

Foram utilizadas 15 rizobactérias isoladas em meio YM (yeast manitol) a partir de nódulos plantas de arroz de sequeiro (Oryza sativa) cultivado no cerrado goiano, pertencentes à coleção do Laboratório de Bioquímica da Universidade Estadual de Goiás, Campus de Ciências Exatas e Tecnológicas em Anápolis. Adicionalmente, foram incluídas cinco estirpes-controle obtidas junto a Embrapa Arroz e Feijão de Santo Antônio de Goiás, destas quatro bactérias do gênero Rhizobium BR322 ( $R$. tropici), BR520 (R. tropici), BR10055 (R. galegae), CFN42 (R. etli) e uma do gênero Mesorhizobium BR522 (Mesorhizobium mediterraneum).

Os meios de cultura utilizados no trabalho estão detalhados na Tabela 1.

TABELA 1. Composição dos meios de cultura avaliados.

\begin{tabular}{ll}
\hline \multicolumn{1}{c}{ Meio } & Composição \\
\hline & $200 \mathrm{mg} \cdot \mathrm{mL}^{-1}$ sulfato de magnésio \\
YM - Yeast Manitol & $100 \mathrm{mg} \cdot \mathrm{mL}^{-1}$ cloreto de sódio \\
(HUNGRIA, ARAÚJO, & $500 \mathrm{mg} \cdot \mathrm{mL}^{-1}$ extrato de levedura \\
$1994)$ & $10 \mathrm{~g} \cdot \mathrm{L}^{-1} \mathrm{manitol}^{-1}$ \\
& $500 \mathrm{mg} \cdot \mathrm{L}^{-1}$ fosfato de potássio monobásico, $\mathrm{pH} 6,5$ \\
& $1000 \mathrm{~mL}$ água destilada \\
\hline & $100 \mathrm{mg} \cdot \mathrm{mL}^{-1}$ sulfato de magnésio \\
RDM $\quad$ Rhizobium & $1,1 \mathrm{~g} \cdot \mathrm{L}^{-1}$ glutamato de sódio \\
Defined Medium & $230 \mathrm{mg} \cdot \mathrm{L}^{-1}$ fosfato de potássio monobásico \\
(CASTELLANE, 2007) & $10 \mathrm{~g} \cdot \mathrm{L}^{-1}$ de sacarose, pH 6,5 \\
& $1000 \mathrm{~mL}^{2}$ água destilada \\
\hline
\end{tabular}


CB - Caldo Batata

(DOBEREINER,

ANDRADE, BALDANI, 1999)
$200 \mathrm{~mL}$ de caldo cozido de $200 \mathrm{~g}$ de batata-inglesa

$2,5 \mathrm{~g} \cdot \mathrm{L}^{-1}$ ácido málico

2,5 g.L ${ }^{-1}$ açúcar cristal comercial

$1 \mathrm{~mL}$ de solução de biotina $0,001 \mathrm{~g} \cdot \mathrm{L}^{-1}$

$2 \mathrm{~mL}$ de solução de micronutrientes $\left(0,2 \mathrm{~g} \cdot \mathrm{L}^{-1}\right.$ de molibidato de sódio, $0,235 \mathrm{~g} \cdot \mathrm{L}^{-1}$ de sulfato de manganês, $0,28 \mathrm{~g} \cdot \mathrm{L}^{-1}$ de ácido bórico, 0,008 g. $\mathrm{L}^{-1} \mathrm{de}$ sulfato de cobre e $0,024 \mathrm{~g} \cdot \mathrm{L}^{-1}$ de sulfato de zinco), $\mathrm{pH} 6,8$.

$800 \mathrm{~mL}$ água destilada

A manutenção das cepas foi realizada com repiques para obtenção de colônias isoladas em meio sólido YM, pela técnica de esgotamento de estrias e incubação das placas a $28{ }^{\circ} \mathrm{C}$ por 24 horas. Após o crescimento, tres a cinco colônias isoladas e típicas foram transferidas para frascos de penicilina estéreis contendo $10 \mathrm{~mL}$ de meio líquido YM. Os frascos com meios de cultura inoculados foram levados ao agitador e incubados a $28{ }^{\circ} \mathrm{C}$ por 24 horas.

Após crescimento em meio líquido, alíquotas de $1,5 \mathrm{~mL}$ do meio crescido foram transferidas para tubos de microcentrífuga previamente esterilizados e rotulados e centrifugados a 13.000 RPM por cinco minutos. Após a centrifugação o sobrenadante foi removido e as células suspendidas em solução glicerol a $30 \%$. Os tubos foram armazenados a $8{ }^{\circ} \mathrm{C}$ por sete dias e posteriormente congelados em freezer a $-40^{\circ} \mathrm{C}$, sendo os estoques renovados a cada seis meses.

As cepas foram reativadas em meio sólido YM, pela técnica de esgotamento de alça bacteriológica. $O$ estoque foi retirado do freezer e deixado na câmara de fluxo laminar até atingirem a temperatura ambiente. Foram pipetados $2 \mathrm{~L}$ do estoque e colocados sobre a placa, as quais foram posteriormente semeadas com auxílio de alças de platina e em seguida incubadas a $28^{\circ} \mathrm{C}$ por 24 horas.

\section{Formação de biofilme bacteriano}

A avaliação da formação de biofilme com quantificação da biomassa total e viabilidade celular foi realizada nos meios de cultura YM, RDM e CB, previamente descritos. Após o crescimento das estirpes, colônias típicas foram ressuspendidas em $5 \mathrm{~mL}$ de solução fisiológica estéril $0,9 \%$ (SFE) e o inóculo ajustado com escala 0,5 McFarland a $1,5 \times 10^{8}$ ufc. $\mathrm{mL}^{-1}$. Posteriormente, foram realizadas diluições seriadas para o ajuste do inóculo a $1,5 \times 10^{5}$ ufc. $\mathrm{mL}^{-1}$.

A formação de biofilme foi realizada em duas microplacas de poliestireno, sendo uma para o teste de biomassa no biofilme e a outra para o teste de viabilidade no biofilme. Foram transferidos $100 \mathrm{~L}$ do inóculo ajustado de cada linhagem bacteriana para os poços de cada placa, sendo as mesmas incubadas por 24 horas a $30{ }^{\circ} \mathrm{C}$. Os testes foram realizados em triplicata em ensaios independentes para cada um dos meios estudados.

Após o período de incubação foi realizada a leitura da densidade óptica dos poços a $630 \mathrm{~nm}$ para a determinação da formação de biomassa total segundo a metodologia descrita por Freire e colaboradores (2018). Em seguida, o meio de cultura crescido foi removido e cada poço foi lavado uma vez com 200 L de solução fisiológica estéril para a remoção das células não aderidas.

Foram adicionados, a cada poço da placa, $100 \mathrm{~L}$ de solução do corante cristal violeta $(\mathrm{CV}) 0,1 \%$. O CV foi deixado em contato com o poço por 15 minutos, em seguida o corante foi removido e cada poço lavado com 200 L de água 
destilada por quatro vezes. As placas foram secas à temperatura ambiente por 15 minutos. Posteriormente, $100 \mathrm{~L}$ de álcool etílico absoluto foram adicionados em cada poço para a solubilização do CV aderido à matriz. A quantificação da biomassa foi realizada por meio da leitura da densidade óptica a $492 \mathrm{~nm}$ e o cálculo do Índice de Formação de Biofilme de acordo com a equação 1.

Equação 1. Cálculo do Índice de Formação de Biofilme (IFB).

$$
\mathrm{IFB}=\frac{A b s_{492}-A b s B r_{492}}{A b s_{630}-A b s B r_{630}}
$$

Sendo:

Abs 492 - Absorbância do poço a $492 \mathrm{~nm}$

$A b s_{630}$ - Absorbância do poço a $630 \mathrm{~nm}$

$A b_{s B r}$ $_{42}$ - Absorbância do poço controle não inoculado a $492 \mathrm{~nm}$

$A_{b s B r}{ }_{630}$ - Absorbância do poço controle não inoculado a $630 \mathrm{~nm}$

\section{Cálculo da Viabilidade Celular no Biofilme (VCB)}

Após o período de incubação, o meio crescido foi removido e cada poço foi lavado uma vez com 200 L de SFE para a remoção das células não aderidas. Após o tratamento inicial, foram adicionados a cada poço de uma das placas, $100 \mathrm{~L}$ de solução de resazurina 200,0 g.mL $\mathrm{mL}^{-1}$ em cada respectivo meio de cultura em que procedeu-se a realização do experimento.

As placas foram então incubadas a $37{ }^{\circ} \mathrm{C}$ por quatro horas. Em seguida procedeu-se à leitura das densidades ópticas dos poços a 570 e $600 \mathrm{~nm}$ para o cálculo da percentagem de metabolização da resazurina. A determinação da porcentagem de metabolização da resazurina foi calculada pela equação 2 (ZIPPERER; RETSCHMER, 2017). A equação em questão leva em consideração a correção para o uso da absorbância em relação ao uso da fluorescência.

Equação 2. Cálculo da viabilidade celular no biofilme.

$$
V C B=\left(\frac{\left(\left(117216 \cdot A b s_{570}\right)-\left(80586 \cdot A b s_{600}\right)\right)}{\left(\left(155677 \cdot A b s B r_{600}\right)-\left(14652 \cdot A b s B r_{570}\right)\right)}\right) \cdot 100
$$

Sendo:

Abs 570 - Absorbância do poço a $570 \mathrm{~nm}$ $A b s_{600}$ - Absorbância do poço a $600 \mathrm{~nm}$

$A b_{s B r}{ }_{570}$ - Absorbância do poço controle não inoculado a $570 \mathrm{~nm}$

$\mathrm{AbsBr}_{600}$ - Absorbância do poço controle não inoculado a $600 \mathrm{~nm}$

\section{RESULTADOS E DISCUSSÃO}

Todas as rizobactérias foram capazes de formar biofilmes nos meios de cultura avaliados. A Figura 2 e Gráfico 1 mostram os resultados obtidos para o índice de formação de biofilme nos diferentes meios de cultura, respectivamente. 
FIGURA 2. Heatmap do índice de formação de biofilmes das rizobactérias nos meios de cultura RDM - Rhizobium defined medium, YM - yeast manitol e CB - caldo batata. Prisma GraphPad Prism 7.04 (Graphpad Software).

\begin{tabular}{|c|c|c|c|}
\hline & 10 & 20 & 30 \\
\hline R30 & $10.23 \pm 0.19$ & $10.31 \pm 0.8$ & $10.17 \pm 1.60$ \\
\hline R31 & $9.09 \pm 0.64$ & $7.69 \pm 1.23$ & $26.43 \pm 1.69$ \\
\hline R54 & $20.06 \pm 0.40$ & $20.75 \pm 0.82$ & $13.99 \pm 1.33$ \\
\hline $\mathbf{R} 58$ & $33.21 \pm 0.45$ & $33.77=1.11$ & $13.14 \pm 1.93$ \\
\hline R59 & $16.11 \pm 0.45$ & $19.12 \pm 0.90$ & $8.98 \pm 1.04$ \\
\hline R65 & $11.79 \pm 0.76$ & $16.37 \pm 1.30$ & $8.39 \pm 0.62$ \\
\hline R73A & $19.04 \pm 0.46$ & $18.21 \pm 1.31$ & $8.49 \pm 1.13$ \\
\hline $\mathbf{R} 80$ & $7.18 \pm 0.42$ & $10.84 \pm 0.69$ & $9.01 \pm 2.04$ \\
\hline R132 & $9.47 \pm 1.50$ & $10.06 \pm 3.51$ & $13.26 \pm 2.87$ \\
\hline R134 & $26.66 \pm 0.72$ & $17.18 \pm 1.79$ & $12.84 \pm 1.80$ \\
\hline R5 & $13.12 \pm 0.42$ & $13.84 \pm 0.84$ & $6.10 \pm 0.56$ \\
\hline R25A & $12.19 \pm 0.75$ & $17.98=1.11$ & $17.55 \pm 1.79$ \\
\hline $\mathbf{R 4 0}$ & $14.78 \pm 0.36$ & $20.34 \pm 0.74$ & $7.26 \pm 0.62$ \\
\hline $\mathbf{R} 82$ & $22.27 \pm 0.21$ & $22.52 \pm 0.73$ & $8.27 \pm 2.21$ \\
\hline R127 & $15.92 \pm 0.37$ & $17.34 \pm 0.88$ & $10.66 \pm 1.50$ \\
\hline BR322 & $29.95 \pm 1.59$ & $11.85 \pm 0.64$ & $3.44 \pm 1.14$ \\
\hline BR520 & $19.34 \pm 0.83$ & $12.89 \pm 0.68$ & $10.69 \pm 1.08$ \\
\hline BR522 & $20.76 \pm 0.26$ & $16.51 \pm 1.13$ & $13.62 \pm 1.25$ \\
\hline BR10055 & $20.93 \pm 0.52$ & $21.09 \pm 0.70$ & $20.52 \pm 2.50$ \\
\hline CFN42 & $15.58 \pm 0.33$ & $21.81 \pm 0.75$ & $18.25 \pm 1.29$ \\
\hline
\end{tabular}

GRAFICO 1. Índices de formação de biofilme das rizobactérias nos meios de cultura avaliados.

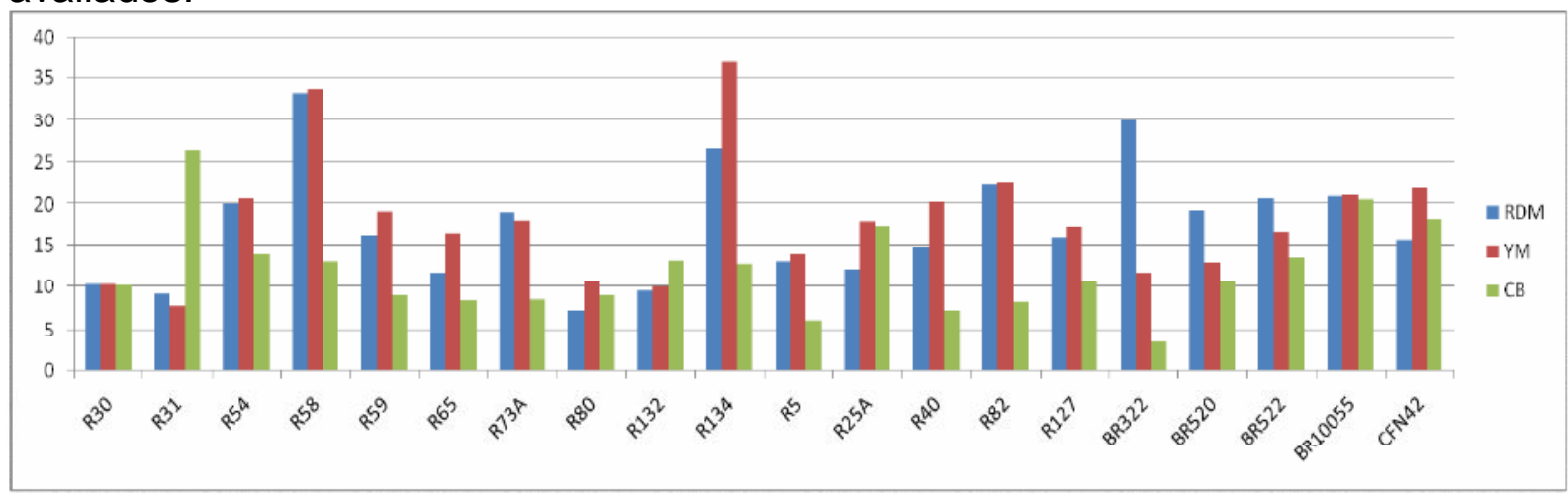

RDM - Rhizobium defined medium; YM - yeast manitol; CB - caldo batata

Os índices de formação de biofilme mais altos foram detectados para a rizobactéria R134 $(37,18 \pm 1,79)$ no meio YM e para as R58 nos meios RDM $(33,21$ 
$\pm 0,44)$ e YM $(33,77 \pm 1,11)$. Os IFB mais baixos foram detectados no caldo batata para as cepas BR322 $(3,44 \pm 1,14)$ e $R 5(6,10 \pm 0,56)$.

De modo a classificar a formação de biofilme, as bactérias foram divididas por meio de critério próprio em grupos de alto IFB (>15\%) e baixo IFB ( $\leq 15 \%)$. Para o meio de cultura RDM 12 mostraram alto IFB e sete baixo IFB. Para o meio de cultura YM 13 cepas apresentaram alto IFB e sete com baixo IFB. No meio caldo batata quatro estirpes apresentaram alto IFB e 16 baixo IFB.

A Figura 3 e o Gráfico 2 mostram os resultados obtidos para a viabilidade celular das bactérias associadas aos biofilmes nos diferentes meios de cultura.

FIGURA 3. Heatmap da viabilidade celular das rizobactérias associadas aos biofilmes nos meios de cultura RDM - Rhizobium defined medium, YM - yeast manitol e CB - caldo batata. Prisma GraphPad Prism 7.04 (Graphpad Software).

\begin{tabular}{|c|c|c|c|c|}
\hline & 20 & 35 & 50 & 65 \\
\hline $\mathbf{R} 30$ & & $59.89 \pm 0.6$ & $65.27 \pm 0.81$ & $47.39 \pm 1.00$ \\
\hline R31 & & $42.16 \pm 0.52$ & $33.93 \pm 0.87$ & $74.74 \pm 1.09$ \\
\hline R54 & & $49.77 \pm 0.81$ & $70.93 \pm 0.55$ & $70.08 \pm 0.57$ \\
\hline R58 & & $65.55 \pm 0.79$ & $67.65 \pm 0.85$ & $60.25 \pm 0.62$ \\
\hline R59 & & $39.98 \pm 0.66$ & $50.12 \pm 0.51$ & $29.16 \pm 0.7$ \\
\hline R65 & & $52.96 \pm 0.74$ & $55.39 \pm 0.73$ & $60.25 \pm 0.69$ \\
\hline R73A & & $61.85 \pm 0.64$ & $60.22 \pm 0.79$ & $64.84 \pm 0.76$ \\
\hline $\mathbf{R} 80$ & & $45.48 \pm 0.73$ & $54.72 \pm 0.57$ & $60.65 \pm 0.56$ \\
\hline R132 & & $18.92 \pm 0.78$ & $20.32 \pm 0.55$ & $17.06 \pm 1.03$ \\
\hline R134 & & $57.43 \pm 0.52$ & $66.62 \pm 1.46$ & $61.12 \pm 0.78$ \\
\hline R5 & & $62.57 \pm 0.47$ & $80.50 \pm 0.51$ & $77.16 \pm 0.58$ \\
\hline R25A & & $21.28 \pm 0.47$ & $22.69 \pm 0.76$ & $21.44 \pm 0.76$ \\
\hline R40 & & $53.15 \pm 0.7$ & $73.12 \pm 0.7$ & $59.89 \pm 0.49$ \\
\hline $\mathbf{R} 82$ & & $77.41 \pm 0.79$ & $70.38 \pm 0.71$ & $70.53 \pm 0.78$ \\
\hline R127 & & $37.38 \pm 0.41$ & $75.07 \pm 0.5$ & $60.67 \pm 0.53$ \\
\hline BR322 & & $31.89 \pm 0.36$ & $29.64 \pm 0.65$ & $31.19 \pm 0.76$ \\
\hline BR520 & & $50.84 \pm 0.74$ & $63.99 \pm 0.75$ & $60.37 \pm 0.56$ \\
\hline BR522 & & $67.75 \pm 0.56$ & $67.93 \pm 0.36$ & $76.85 \pm 0.6$ \\
\hline BR10055 & & $47.56 \pm 0.64$ & $55.52 \pm 0.44$ & $59.61 \pm 0.48$ \\
\hline \multirow[t]{2}{*}{ CFN42 } & & $41.40 \pm 0.8$ & $64.61 \pm 0.9$ & $63.38 \pm 0.61$ \\
\hline & & مه & st & $0^{8}$ \\
\hline
\end{tabular}


GRÁFICO 2. Viabilidade celular das rizobactérias associadas aos biofilmes nos meios de cultura avaliados.

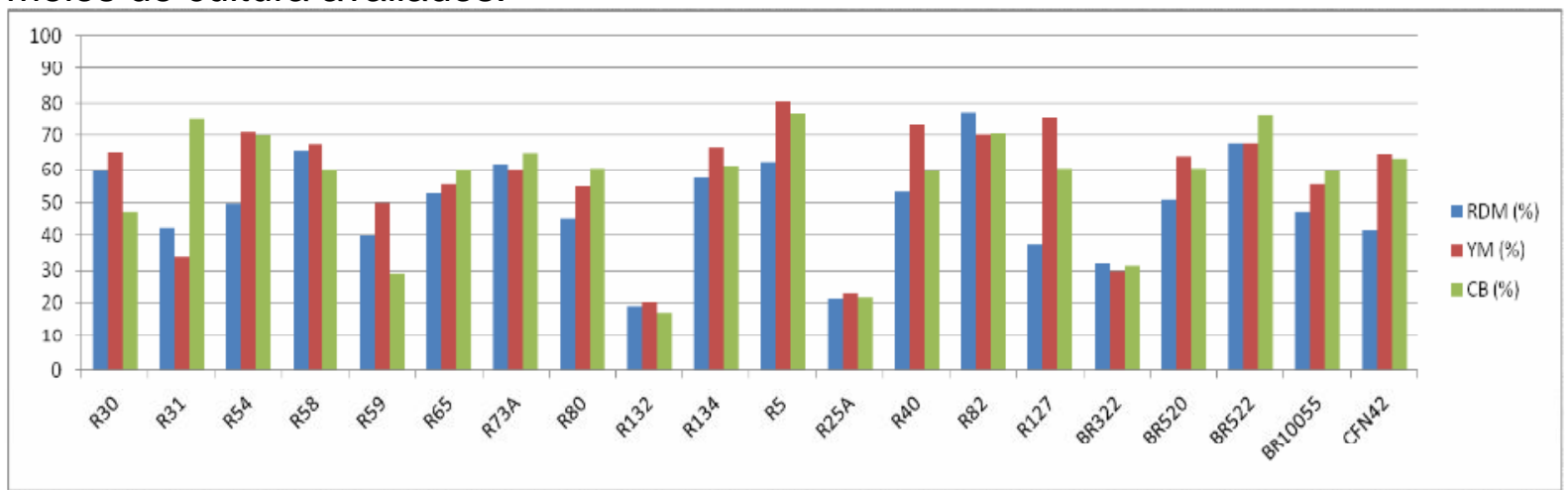

RDM - Rhizobium defined medium; YM - yeast manitol; CB - caldo batata

As rizobactérias com a maior porcentagem de leitura da viabilidade das células associadas aos biofilmes foram R82 $(77,41 \pm 0,79)$ em RDM, BR522 $(76,85 \pm$ $0,60)$ e R31 $(74,74 \pm 1,09)$ no caldo batata e R127 $(75,07 \pm 0,50)$ em meio YM. Por outro lado, as menores leituras foram para R132 e R125a em todos os meios e para R59 em caldo batata.

No estudo da viabilidade celular, cepas que mostraram VCB maior que $50 \%$ foram consideradas de alta viabilidade, dessa forma 10 cepas foram consideradas de alta viabilidade no meio RDM, 16 no meio YM e 14 no meio caldo batata (Tabela 3).

O meio RDM proporcionou desempenho mais discreto entre os meios testados quando considerado a VCB, com apenas uma cepa com valor mais elevado e nenhuma em relação à $\mathrm{BMT}$, entretanto foi superior ao $\mathrm{CB}$ quando levado em consideração o IFB, com cinco estirpes apresentando este índice mais elevado.

O Gráfico 3 mostra a correlação entre IFB e VC.

GRÁFICO 3. Correlação entre os índices de formação do biofilme e a viabilidade celular das rizobactérias associadas aos biofilmes nos meios de cultura avaliados.

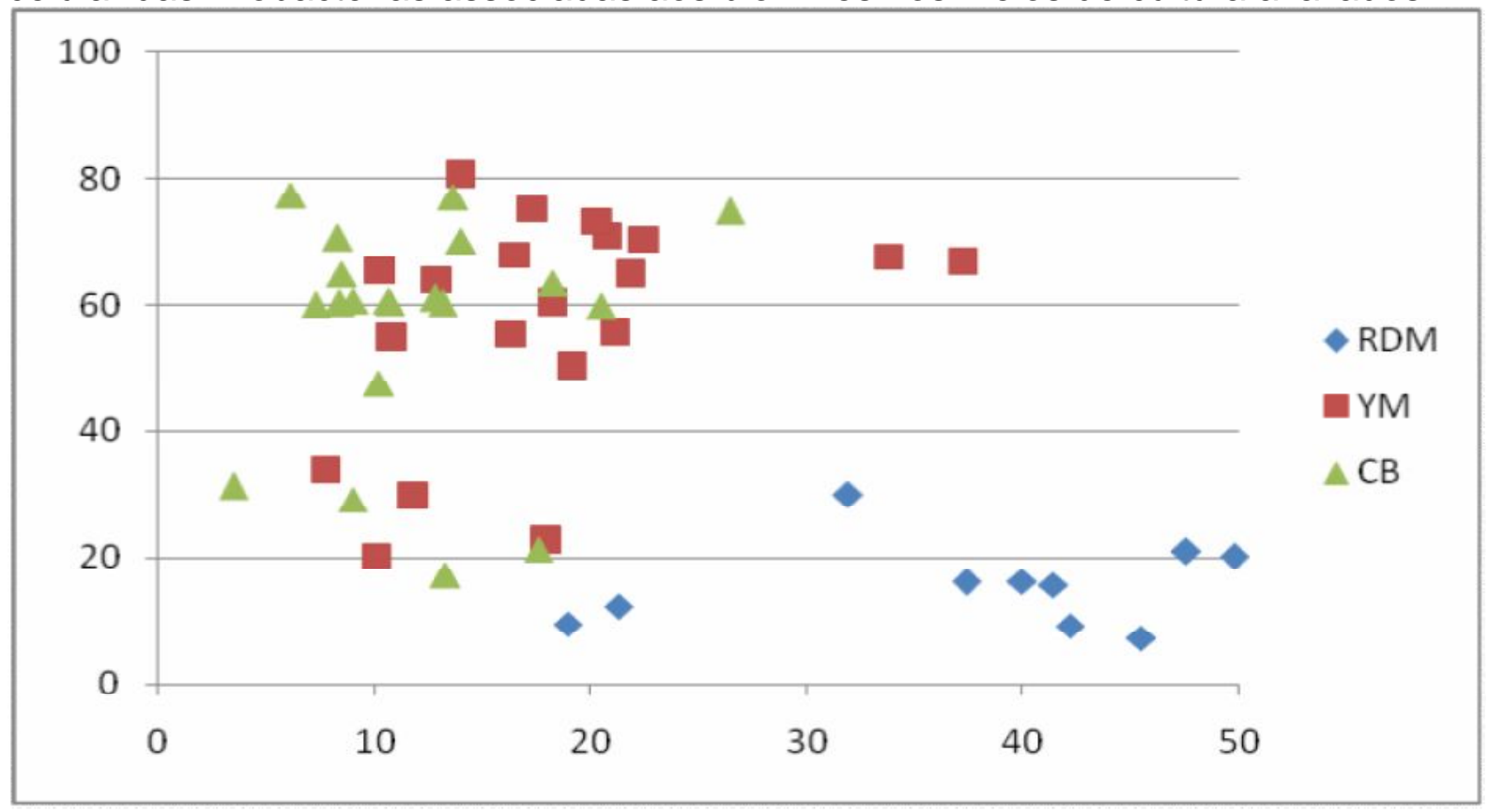


Pode-se inferir que no grupo avaliado, a viabilidade celular pode ser considerada elevada para a grande maioria das bactérias avaliadas nos meios YM e CB. Tais resultados indicam que a composição destes meios de cultura é mais adequada às necessidades fisiológicas das bactérias, no que diz respeito à síntese de compostos para sua subsistência na forma séssil, explicando seu melhor desempenho na VCB.

A formação de biofilme no caldo batata, provavelmente é influenciada devido ao aumento da densidade populacional em relação ao tempo de incubação, fato que pode ser o indicador para o estabelecimento e indução da formação de biofilme, em resposta ao intenso crescimento que este meio proporcionou, ou seja, a formação neste caso pode ser dependente da taxa de crescimento celular.

De modo geral a formação de biofilme pode ser considerada baixa para todo o grupo avaliado, tal fato pode ser atribuído à inibição por repressão catabólica, possivelmente como um indicador de que as células estão em um ambiente rico em nutrientes, não sendo necessária a formação do biofilme, pois em modo planctônico há maior área de superfície de células expostas aos nutrientes (KOUR et al., 2020).

A correlação entre IFB e VCB a partir da classificação acima possibilitou a divisão das estirpes em quatro grupos. No primeiro grupo estão bactérias com alto IFB e VCB, o segundo baixo IFB e baixa VCB e o terceiro alto IFB e baixo VCB e no quarto grupo baixo IFB e alto VCB.

Para o meio RDM sete estirpes foram alocadas no grupo 1, quatro no grupo 2 , seis no grupo 3 e três no grupo 4. Para o meio YM 12 foram colocadas no grupo 1 , três no grupo 2, uma no grupo 3 e quatro no grupo 4. Para o meio caldo batata duas estirpes foram alocadas no grupo 1, quatro no grupo 2, duas no grupo 3 e 12 no grupo 4. A Tabela 2 apresenta a correlação entre os índices de formação de biofilme e viabilidade celular no biofilme nos meios de cultura avaliados.

TABELA 2. Correlação entre os índices de índice de formação de biofilme e viabilidade celular no biofilme nos meios de cultura avaliados.

\begin{tabular}{llccc}
\hline \multicolumn{1}{c}{ Índices } & \multicolumn{4}{c}{ Meios de Cultura } \\
\hline IFB & VCB & RDM & YM & CB \\
\hline Alto & Alto & 7 & 12 & 2 \\
Baixo & Baixo & 4 & 3 & 4 \\
Alto & Baixo & 6 & 1 & 2 \\
Baixo & Alto & 3 & 4 & 12 \\
\hline
\end{tabular}

IFB - Índice de Formação de Biofilme; VCB - Viabilidade Celular no Biofilme; RDM Rhizobium defined medium; YM - yeast manitol; CB - caldo batata.

Estatisticamente por meio do teste de Fisher, somente quando considerado o IFB, foram observadas diferenças significativas entre o meio $C B$ e os demais $(p=$ 0,0095). Quando comparados os meios RDM e CB, por meio do teste de Fisher, observou-se que o segundo foi mais eficiente na viabilidade celular $(P=0,0217)$. Também foram observadas diferenças significativas nos parâmetros de IFB, BMT e crescimento celular entre os dois meios $(P=0,0001)$.

Já a comparação entre os meios RDM e YM, demonstrou que o YM é mais eficiente para manutenção da viabilidade celular no biofilme $(P=0,0077)$, no BMT ( $P$ $=0,0001)$ e crescimento total $(P=0,0112)$. Contudo não foi observada diferença significativa para IFB entre esses dois meios.

$\mathrm{Na}$ análise entre os meios $\mathrm{CB}$ e $\mathrm{YM}$, constatou-se que houve diferença significativa para os parâmetros de BMT $(P=0,0125)$ e crescimento celular $(P=$ 
0,0001), sendo o CB mais efetivo nestes dois quesitos. O parâmetro de IFB também foi estatisticamente significativo na comparação destes dois meios ( $P=0,0001)$, sendo o meio YM mais efetivo neste quesito. Não são observadas diferenças estatisticamente significantes entre os meios CB e YM na viabilidade celular em biofilme.

Condições de formação de biofilme induzida em condições de riqueza de nutrientes são relatadas por Poole et al. (2018), que sugerem que as bactérias iniciam a formação de biofilme em resposta a sinais ambientais, tais como disponibilidade e tipo de nutrientes, temperatura, $\mathrm{pH}$ e oxigênio. Esse autor ainda relata que micro-organismos que formam biofilme em meio rico em nutrientes quando em situações de escassez se desprendem do biofilme e retornam ao modo de vida isolado, provavelmente em busca de novas fontes de nutrientes.

Por outro lado, a capacidade de espécies bacterianas de se coordenarem como biofilme, atribui a elas características de um organismo multicelular, trazendo vantagens para a população bacteriana como um todo. As células bacterianas que vivem em biofilmes têm maior resistência a vários agentes antimicrobianos e estão melhores adaptadas a sobreviver a períodos de estresse ambiental (KOUR et al., 2020).

Quando há a disponibilidade e fornecimento de nutrientes, as bactérias promovem um constante desenvolvimento do biofilme (RAJANBIR, RAJANBIR, 2020). Em contraste, há casos em que a indução da formação de biofilme ocorre quando há baixa concentração de nutrientes. Sendo assim, a disponibilidade de nutrientes desempenha um papel importante na transição a partir de um modo de vida planctônico para um modo séssil, sendo a formação de biofilme regulada por sinais que diferem entre as espécies bacterianas e que refletem o habitat em que as mesmas estão expostas (KOUR et al., 2020).

Este trabalho auxilia na otimização das condições de cultivo para a formação de biofilme in vitro por rizobactérias, uma vez que diversos parâmetros foram avaliados em três dos principais meios de cultivo para essas bactérias.

Dedicado à memória da profa. Cláudia Cristina Garcia Martin Didonet

\section{REFERÊNCIAS}

AERON, A.; KHARE, E.; JHA, C. K.; MEENA, V. S. et al. Revisiting the plant growthpromoting rhizobacteria: lessons from the past and objectives for the future. Archives of microbiology, v. 202, n. 4, p. 665-676, 2020.Disponível em: https://doi.org/10.1007/s00203-019-01779-w

ALOO, N.; MAKUMBA, B. A.; MBEGA, E. R. The potential of Bacilli rhizobacteria for sustainable crop production and environmental sustainability. Microbiological Research, v. 219, p. 26-39, 2019. Disponível em: https://doi.org/10.1016/j.micres.2018.10.011

BOURIGAULT, Y.; RODRIGUES, S; CRÉPIN, A.; CHANE, A.; TAUPIN, L. et al. Biocontrol of Biofilm Formation: Jamming of Sessile-Associated Rhizobial Communication by Rhodococcal Quorum-Quenching. International journal of molecular sciences, v. 22, n. 15, p. 8241, 2021. Disponível em: https://doi.org/10.3390/ijms22158241 
CASTELLANE, T. C. Análise de Polissacarídeos Essenciais para a Nodulação do Feijoeiro por Rhizobium tropici Cultivados em Diferentes Fontes de Carbono. Jaboticabal, São Paulo, Dissertação Mestrado, 2007. Faculdade de Ciências Agrárias e Veterinárias, 88 p. Disponível em: http://hdl.handle.net/11449/96949

CHOUDHARY, P.; SINGH, S.; AGARWAL, V. Microbial Biofilms. In: Bacterial Biofilms. IntechOpen, 2020. DOI: http://dx.doi.org/10.5772/intechopen.90790

COSTA, K. A. D.; FERENZ, M.; SILVEIRA, S. M.; MILLEZI, A. F. Bacterial biofilm formation in different surfaces of food industries. Revista do Instituto de Laticínios Cândido Tostes, v. 71, n. 2, p. 75-82, 2016. Disponível em: https://doi.org/10.14295/2238-6416.v71i2.512

DÖBEREINER, J.; ANDRADE, V. O.; BALDANI; V. L. D. Protocolos para preparo de meios de cultura da Embrapa Agrobiologia. Embrapa Agrobiologia-Documentos (INFOTECA-E), 1999. Disponível em: https://www.embrapa.br/busca-depublicacoes/-/publicacao/624371/protocolos-para-preparo-de-meios-de-cultura-daembrapa-agrobiologia

FREIRE, F. E. C.; NETO, J. H. A.; SILVA, D. P.; GONÇALVES, R. C.; MENEZES, A. C. S.; NAVES, P. L. F. Atividade do ácido 3, 4, 5-triacetobenzóico contra a formação de biofilmes bacterianos. Revista Virtual de Química, v. 10, n. 4, 2018. Disponível em: https://doi.org/10.21577/1984-6835.20180056

GOUDA, S.; KERRY, R. G.; DAS, G.; PARAMITHIOTIS, S.; SHINE, H. S.; PATRA, J. $\mathrm{K}$. Revitalization of plant growth promoting rhizobacteria for sustainable development in agriculture. Microbiological research, v. 206, p. 131-140, 2018. Disponível em: https://doi.org/10.1016/j.micres.2017.08.016

HATHROUBI, S.; SERVETAS, S. L.; WINDHAM, I.; MERRELL, D. S.; OTTEMANN, K. M. Helicobacter pylori biofilm formation and its potential role in pathogenesis. Microbiology and Molecular Biology Reviews, v. 82, n. 2, p. e00001-18, 2018. Disponível em: https://doi.org/10.1128/MMBR.00001-18

HUNGRIA, M.; ARAÚJO, R. S. Manual de Métodos Empregados em Estudos De Microbiologia Agrícola. Empresa Brasileira de Pesquisa Agropecuária $1^{\circ}$ Ed. Ed. Centro Nacional de Pesquisa de Arroz e Feijão, Centro Nacional de Pesquisa de Soja. Brasília, p. 45-57, 95-131, 157-170, 1994. Disponível em: https://www.bibliotecaagptea.org.br/agricultura/biologia/livros/MICRORGANISMOS\% 20DE\%20IMPORTANCIA\%20AGRICOLA.pdf

KOUR, D; RANA, K. L.; KAUR, T.; YADAV, N.; YADAV, A. N. et al. Chapter 18 Microbial biofilms: Functional annotation and potential applications in agriculture and allied sectors, Editor(s): Mukesh Kumar Yadav, Bhim Pratap Singh, New and Future Developments in Microbial Biotechnology and Bioengineering: Microbial Biofilms, Elsevier, 2020, Pages 283-301, ISBN 9780444642790. Disponível em: https://doi.org/10.1016/B978-0-444-64279-0.00018-9. 
MUHAMMAD, M. H.; IDRIS, A. L.; FAN, X.; GUO, Y.; YU, Y. et al. Beyond risk: bacterial biofilms and their regulating approaches. Frontiers in microbiology, v. 11, p. 928, 2020. Disponível em: https://doi.org/10.3389/fmicb.2020.00928

MUHSIN, J.; WISAL, A.; SAADIA, A.; FAZALB, J.; MURAMMADE, I. et al. Bacterial biofilm and associated infections. Journal of the Chinese Medical Association, v. 81, n. 1, p. 7-11, 2018. Disponível em: https://doi.org/10.1016/j.jcma.2017.07.012

NUMAN, M.; BASHIR, S.; KHAN, Y.; MUNTAZ, R.; SHINWARI, Z. K. et al. Plant growth promoting bacteria as an alternative strategy for salt tolerance in plants: a review. Microbiological research, v. 209, p. 21-32, 2018. Disponível em: https://doi.org/10.1016/j.micres.2018.02.003

PEETERS, E.; NELIS, H. J.; COENYE, T. Comparison of multiple methods for quantification of microbial biofilms grown in microtiter plates. Journal of microbiological methods, v. 72 , n. 2, p. 157-165, 2008. Disponível em: https://doi.org/10.1016/j.mimet.2007.11.010

POOLE, P.; RAMACHANDRAN, V.; TERPOLILLI, J. Rhizobia: from saprophytes to endosymbionts. Nature Reviews Microbiology, v. 16, n. 5, p. 291-303, 2018. Disponível em: https://doi.org/10.1038/nrmicro.2017.171

RAJANBIR, K; RAJANBIR, K. Microbial Diversity and their Biofilm Formation Potential in Pipes of Water Distribution System. Asian Journal of Water, Environment and Pollution, v. 17, n. 4, p. 113-117, 2020. Disponível em: https://doi.org/10.3233/AJW200058

REZENDE, C. C.; SILVA, M. A.; FRASCA, L. L. M.; FARIA, D. R.; FILIPPI, M. C. C. et al. Multifunctional microorganisms: use in agriculture. Research, Society and Development, v. 10, n. 2, p. e50810212725-e50810212725, 2021. Disponível em: https://doi.org/10.33448/rsd-v10i2.12725

WANG, X.; LV, S.; LIU, T.; WEI, J.; QU, S. et al. CRISPR/Cas9 genome editing shows the important role of AZC_2928 gene in nitrogen-fixing bacteria of plants. Functional \& Integrative Genomics, v. 20, p. 657-668, 2020. Disponível em: https://doi.org/10.1007/s10142-020-00739-8

ZIPPERER, A.; KRETSCHMER, D. Cytotoxicity assays as predictors of the safety and efficacy of antimicrobial agents. In: Antibiotics. Humana Press, New York, NY, 2017. p. 107-118. Disponível em: https://doi.org/10.1007/978-1-4939-6634-9_6 